\title{
Bovine Serum Albumin and Chitosan Coated Silver Nanoparticles and Its Antimicrobial Activity against Oral and Nonoral Bacteria
}

\author{
León Francisco Espinosa-Cristóbal, ${ }^{1}$ Gabriel Alejandro Martínez-Castañón, ${ }^{2}$ \\ Juan Pablo Loyola-Rodríguez, ${ }^{2}$ Nereyda Niño-Martínez, ${ }^{3}$ Facundo Ruiz, ${ }^{3}$ \\ Norma Verónica Zavala-Alonso, ${ }^{2}$ René H. Lara, ${ }^{4,5}$ and Simón Yobanny Reyes-López ${ }^{6}$ \\ ${ }^{1}$ Departamento de Estomatología, Instituto de Ciencias Biomédicas, Universidad Autónoma de Ciudad Juárez (UACJ), \\ Envolvente del PRONAF y Estocolmo s/n, 32310 Ciudad Juárez, CHIH, Mexico \\ ${ }^{2}$ Facultad de Estomatología, Universidad Autónoma de San Luis Potosí (UASLP), Avenida Manuel Nava 2, Zona Universitaria, \\ 78290 San Luis Potosí, SLP, Mexico \\ ${ }^{3}$ Facultad de Ciencias, Universidad Autónoma de San Luis Potosí (UASLP), Avenida Manuel Nava 6, Zona Universitaria, \\ 78290 San Luis Potosí, SLP, Mexico \\ ${ }^{4}$ Facultad de Ciencias Químicas, Universidad Juárez del Estado de Durango (UJED), Avenida Veterinaria S/N, Circuito Universitario, \\ 34120 Durango, DGO, Mexico \\ ${ }^{5}$ Facultad de Odontología, Universidad Juárez del Estado de Durango (UJED), Avenida Predio Canoas S/N, Colonia Los Ángeles, \\ 34076 Durango, DGO, Mexico \\ ${ }^{6}$ Instituto de Ciencias Biomédicas, Universidad Autónoma de Ciudad Juárez (UACJ), Envolvente del PRONAF y Estocolmo s/n, \\ 32310 Ciudad Juárez, CHIH, Mexico
}

Correspondence should be addressed to León Francisco Espinosa-Cristóbal; leohamet@hotmail.com

Received 23 July 2015; Revised 5 November 2015; Accepted 8 November 2015

Academic Editor: Rajender S. Varma

Copyright (C) 2015 León Francisco Espinosa-Cristóbal et al. This is an open access article distributed under the Creative Commons Attribution License, which permits unrestricted use, distribution, and reproduction in any medium, provided the original work is properly cited.

\begin{abstract}
Antimicrobial agents have been developed for drug-resistance infections, which have been rapidly increasing; however, the control of involved microorganisms is still a challenge. In this work, SNP with bovine serum albumin (BSA) and chitosan (CS) coatings were prepared with an aqueous reduction method, characterized using dispersion light scattering, transmission electron microscopy, and thermal analysis. Antibacterial activity was tested on seven oral and nonoral bacteria by microdilution test and scanning electron microscopy. Six different sizes and shapes of coated SNP were prepared and used. Characterization revealed narrow size and good distribution of particles, spherical and pseudospherical shapes, and the presence of coatings on the SNP surfaces. All samples showed antimicrobial activity, although smaller sizes and CS samples had the best inhibition effects. The highest microbial resistance was shown by Gram-positive bacteria. Although coated SNP action depends on particular bacterium, BSA and CS coated SNP could be used for drug-resistance infections.
\end{abstract}

\section{Introduction}

Nowadays the increase in bacterial drug resistance is considered a serious health problem concern worldwide. Multiple antibiotic-resistant bacteria are rapidly developing resistance to clinically useful antimicrobials and making them ineffective, reaching alarming limits to antimicrobial therapeutics
[1]. Staphylococcus aureus (S. aureus) has been one of the most frequent drug-resistant bacteria in infections acquired from nosocomial institutions and community, including superficial skin and other soft tissue infections, toxic shock, pneumonia, endocarditis, and septicemia [2]. Escherichia coli (E. coli) is the most common pathogen causing serious intestinal and extraintestinal infections; it possesses several 
virulence factors that are necessary for resistance, survival, and colonization of the bacteria, overcoming host defenses [3]. Enterococcus faecalis (E. faecalis) is also one of the most common bacteria found in clinical setting, responsible for approximately $80 \%$ of enterococcal infections; it has been associated with endodontic infections after root canal treatments showing multidrug resistance $[4,5]$. Moreover, Streptococcus mutans (S. mutans) and Streptococcus sobrinus ( $S$. sobrinus) have been considered as principal oral pathogens involved in the beginning and development of dental caries [6]; they have shown specific levels of bacterial resistance to antibiotics [7].

Several improved treatments for prevention and control of the microorganisms described above have been relevantly successful protocols in many countries of the world $[3,8,9]$ although other alternative approaches of treatments should be investigated for microbial resistance. An option is to use silver nanoparticles (SNP) due to their great bactericidal effect in a wide range of microorganisms including drugresistant bacteria $[10,11]$. It has been reported that SNP could show toxic effects in human cells depending on their physical and chemical properties $[12,13]$; therefore, several studies have designed new nanostructured materials using biocompatible components [14]. Different organic materials have been employed to modify nanoparticles properties through surface modification [15]. Two of them are bovine serum albumin (BSA) and chitosan (CS); the former is a protein with a wide range of physiological functions [16] and the latter is a biopolymer with very important biological properties [17]. Various studies have successfully designed new and novel nanomaterials using different methods for green synthesis $[18,19]$; however, limited information of the antibacterial activity of SNP with BSA and CS coatings on drug-resistant microorganisms is available considering SNP as relevant antimicrobial agents for potential medical uses. In the present work, different sizes and shapes of coated SNP using BSA and CS compounds were prepared and characterized. Antimicrobial activity of the coated SNP was determined by minimal inhibitory concentrations (MIC) using S. aureus, E. coli, E. faecalis, S. mutans, S. sobrinus, $S$. oralis, and $S$. salivarius strains.

\section{Materials and Methods}

2.1. Materials and Reagents. Silver nitrate $\left(\mathrm{AgNO}_{3}, \mathrm{CTR}\right.$ Scientific), bovine serum albumin (BSA, Sigma-Aldrich), chitosan (low molecular weight $85 \%$, Sigma-Aldrich), gallic acid $\left(\mathrm{C}_{7} \mathrm{H}_{6} \mathrm{O}_{5}\right.$, Sigma-Aldrich), acetic acid $\left(\mathrm{C}_{2} \mathrm{H}_{4} \mathrm{O}_{2}, 99.7 \%\right.$, J. T. Baker), brain-heart infusion (BHI, DIFCO Laboratories, Detroit, MI, USA), S. aureus (ATCC, 29213), E. coli (ATCC, 25922), E. faecalis (ATCC, 29212), S. mutans (ATCC, 25175), S. sobrinus (ATCC, 27351), S. oralis (ATCC, 10557), and S. salivarius (NCTC, 8618) strains were purchased, used, and stored according to manufacturer's recommendations. All used reagents were of analytical grades. Deionized water (18 M) was prepared using a Milli-Q Biocel Purification System.

2.2. Silver Nanoparticles Preparation. All preparations started with a $0.01 \mathrm{M} \mathrm{AgNO}_{3}$ solution were placed in a $250 \mathrm{~mL}$ reaction vessel. Under magnetic stirring, $10 \mathrm{~mL}$ of deionized water containing gallic acid $(0.1 \mathrm{~g}$ for first size sample and $0.5 \mathrm{~g}$ for second size sample) was added to $100 \mathrm{~mL} \mathrm{Ag}^{+}$ solution. Afterwards, solution's $\mathrm{pH}$ value was immediately adjusted (for first size sample the $\mathrm{pH}$ was raised to 11 with $\mathrm{NaOH} 1.0 \mathrm{M}$ and for second size sample $\mathrm{pH}$ was raised to 10 with $\mathrm{NH}_{4} \mathrm{OH}$ ) [20]. Later, first and second size suspensions were agglomerated using nitric acid (63\%) to reach a $\mathrm{pH}$ 1.5; all suspensions were filtrated using nitrocellulose filter (Millipore, $0.1 \mu \mathrm{m}$ pore) in a vacuum filter flask and SNP suspensions on the filter were washed several times with deionized water to reach $\mathrm{pH}$ 8; finally, membranes with SNP solutions were redispersed and diluted to a metered volume. SNP with pseudospherical shape and big size were also synthesized. This preparation began with a $0.01 \mathrm{M} \mathrm{AgNO}_{3}$ solution placed in a $250 \mathrm{~mL}$ reaction vessel; under magnetic stirring, gallic acid was added to $100 \mathrm{~mL}$ of $\mathrm{Ag}^{+}$solution and immediately was irradiated with UV light $(254 \mathrm{~nm}, 15 \mathrm{~W})$ during $30 \mathrm{~min}$ ( $\mathrm{pH}$ was not modified), and it was heated during $30 \mathrm{~min}$ at $80^{\circ} \mathrm{C}$ [20]. Finally, solution was centrifuged at $9000 \mathrm{rpm}$ for 10 minutes (Biofuge, USA) and washed three times to discard supernatants; particles were redispersed and diluted to a meter volume with deionized water.

2.2.1. Preparation of BSA Coated SNP. A solution containing $1 \%(\mathrm{wt} / \mathrm{v})$ of BSA was made using deionized water. Three different sizes of SNP and 1\% of BSA solutions were mixed in tubes of $50 \mathrm{~mL}$ according to the following proportions (SNP/BSA): $7: 1$ for first sample; $14: 1$ for second sample, and $7: 1$ for third sample, respectively. Each solution was mixed for $12 \mathrm{~h}$ on an electronic mixer at environmental temperature.

2.2.2. Preparation of CS Coated SNP. CS solutions with different concentrations of acetic acid were prepared by dissolving purified CS in $1 \%, 0.5 \%$, and $0.25 \%$ acetic acid solutions to reach a concentration of $1 \%(\mathrm{wt} / \mathrm{v})$ under magnetic stirring for $12 \mathrm{~h}$ until solutions were transparent. Once dissolved, each solution was placed in different proportions (SNP/CS). To obtain CS coated SNP in smaller size (first sample), a solution containing $0.5 \%$ of acetic acid dissolved with $1 \%$ of CS was mixed with first size of SNP in a proportion of $56: 1$ (SNP/CS); for second size of CS coated SNP, a solution containing $0.5 \%$ of acetic acid with $1 \%$ of CS was collocated with the second size of SNP in a proportion of 28:1 and finally, for bigger size of CS coated SNP, an acetic acid solution of $0.25 \%$ dissolved with $1 \%$ of CS was placed with third size of SNP in a proportion of $28: 1$, respectively. Each solution was mixed for $12 \mathrm{~h}$ on an electronic mixer at environmental temperature. Each procedure for BSA and CS samples was made in three different times.

2.3. Characterization. Ultraviolet-visible (UV-Vis) absorption spectroscopy analysis was used in nanoparticles samples dispersed in water using a UV-Vis spectrometer (CHEMUSB4-VIS-NIR, Ocean Optics) with an integrated lamp of visible light. Dynamic light scattering assay (DLS, Malvern Zetasizer Nano ZS, Instruments Worcestershire, United Kingdom) operating with a $\mathrm{He}-\mathrm{Ne}$ laser at a wavelength of $633 \mathrm{~nm}$ and a detection angle of 90 degrees 
TABLE 1: Physical and chemical properties of BSA and CS coated SNP.

\begin{tabular}{lcccc}
\hline SNP sample $(\mathrm{nm})$ & Diameter DLS $(\mathrm{nm})$ & Diameter TEM $(\mathrm{nm})$ & Shape & Zeta potential $(\mathrm{mV})$ \\
\hline $10.7^{*}$ & 10.7 & - & - & $-22.7 \pm 8.2$ \\
$38.3^{*}$ & 38.3 & - & - & $-15.4 \pm 12.9$ \\
$110.8^{*}$ & 110.8 & - & Spherical & $-24.0 \pm 5.6$ \\
BSA 22.9 & $22.9 \pm 8.5$ & $11.0 \pm 3.2$ & Spherical & $-21.2 \pm 7.7$ \\
BSA 32.7 & $32.7 \pm 8.3$ & $19.4 \pm 5.2$ & Pseudospherical & $-20.9 \pm 5.8$ \\
BSA 113.3 & $113.3 \pm 39.3$ & $94.4 \pm 17.6$ & Spherical & $-19.1 \pm 5.4$ \\
CS 29.7 & $29.7 \pm 12.1$ & $11.9 \pm 2.7$ & Spherical & $17.3 \pm 5.4$ \\
CS 41.0 & $41.0 \pm 6.8$ & $27.6 \pm 4.1$ & Pseudospherical & $36.5 \pm 5.6$ \\
CS 116.6 & $116.6 \pm 4.6$ & $96.0 \pm 13.5$ & $22.0 \pm 6.8$ \\
\hline
\end{tabular}

Diameters and zeta potential are expressed in average and standard deviation; ${ }^{*}$ noncoated samples were prepared one time only; DLS: Dynamic Lighting Scattering; TEM: Transmission Electron Microscopy. -: not applicable.

for 60 seconds at $25^{\circ} \mathrm{C}$ for each sample was performed to confirm size and zeta potential. Transmission Electron Microscopy (TEM, JEOL JEM-1230, Tokyo, Japan) at an accelerating voltage of $100 \mathrm{kV}$ determined shape of particle. Thermogravimetric analysis (TGA) and differential scanning calorimetry (DSC) analysis were used in dehydrated coated and noncoated SNP samples using a DSC calorimeter (Brand Waters Model DSC 500) with a constant heating rate of $20^{\circ} \mathrm{C} / \mathrm{min}$ at room temperature to $1000^{\circ} \mathrm{C}$ under nitrogen atmosphere in a range of temperature from $20^{\circ} \mathrm{C}$ to $510^{\circ} \mathrm{C}$.

2.4. Antibacterial Assay. Seven bacterial strains of S. aureus, E. coli, E. faecalis, S. mutans, S. sobrinus, S. oralis, and $S$. salivarius were tested. Previously to the antimicrobial test, the identity of all microorganisms was confirmed by polymerase chain reaction (PCR). The antibacterial test used in this study was previously reported [20] and some modifications were made. Bacterial strains were cultured in $\mathrm{BHI}$ by $18 \mathrm{~h}$ at $37^{\circ} \mathrm{C}$ before the test. MIC were determined by incubating each microorganism in 96-well microdilution plates; $200 \mu \mathrm{L}$ of each SNP dispersion was placed in the first column and it was diluted 1:1 with BHI medium (containing $2 \%$ of sucrose for oral bacteria) inoculated with each microorganism strain at $6 \times 10^{5} \mathrm{CFU} / \mathrm{mL}$; finally, plates were incubated at $37^{\circ} \mathrm{C}$ for $24 \mathrm{~h}$. After that, the last well that presented turbidity was considered as minimum inhibitory concentration (MIC). To confirm MIC results for oral bacteria (E. faecalis, S. mutans, S. sobrinus, S. oralis, and S. salivarius), wells were washed with phosphate buffer solution (PBS) and fixed with $0.1 \%$ glutaraldehyde for $5 \mathrm{~min}$; and then wells were washed with PBS once and stained using $0.5 \%$ crystal violet confirming antimicrobial activity in the last well that presented coloration. All antibacterial tests were made in triplicate.

2.5. Scanning Electron Microscopy. S. mutans cells were observed using scanning electron microscopy (SEM) after their exposition to SNP. Wells with SNP samples at MIC for smaller coated (BSA $22.9 \mathrm{~nm}$ and CS $29.7 \mathrm{~nm}$ ) and noncoated $(10.7 \mathrm{~nm}) \mathrm{SNP}$ and negative control well were prepared using $0.1 \%$ glutaraldehyde for 5 minutes, washed with PBS ( $\mathrm{pH}$ 7.4), and immersed in solutions with increasing ethanol concentrations $(50,60,70,90,95$, and 100\%) during 20 minutes at $4^{\circ} \mathrm{C}$. Finally, they were air dried and sputter coated

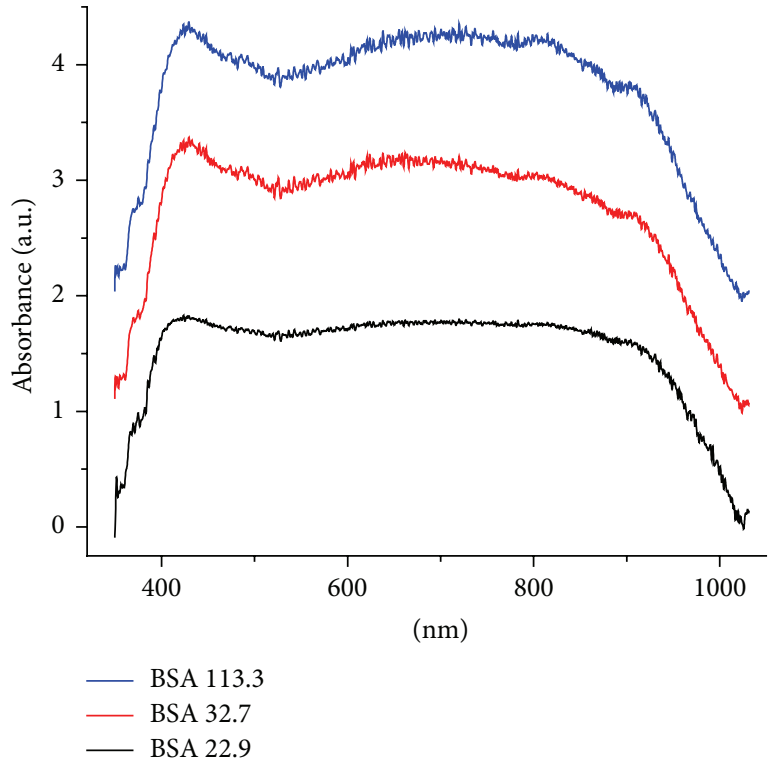

FIGURE 1: UV-Vis spectra of BSA coated SNP.

with a gold layer. Micrographs were taken with a SEM (JEOL JSM-6510) at an accelerating voltage of $20 \mathrm{kV}$.

\section{Results and Discussion}

3.1. UV-Vis and DLS Analysis. UV-Vis spectra of coated SNP are shown in Figure 1. SNP samples showed the characteristic surface plasmon of Ag nanometric (430 nm for larger SNP and $425 \mathrm{~nm}$ for smaller sample); however, the presence of biomolecules can promote larger bands from 600 to $800 \mathrm{~nm}$. The presence of the characteristic surface plasmon confirms good stability and dispersion of SNP samples. DLS results of coated SNP are shown in Table 1. BSA and CS coated SNP samples showed narrow size distributions and the average sizes obtained were slightly bigger in BSA and CS coated SNP samples than those without coatings but there were no representative changes in their original shapes (Figure 2). Zeta potential values showed low negative values in BSA coated SNP compared to noncoated samples increasing 


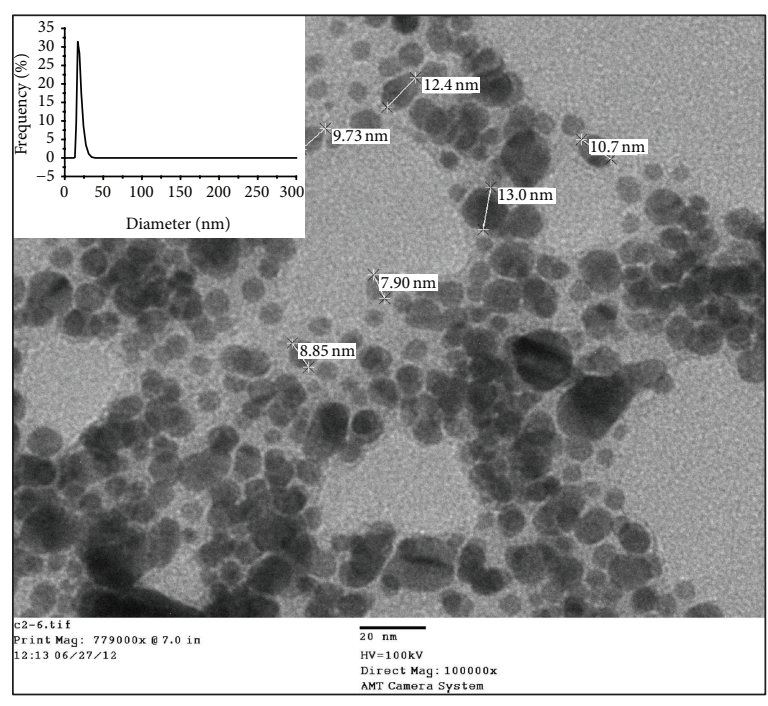

(a)

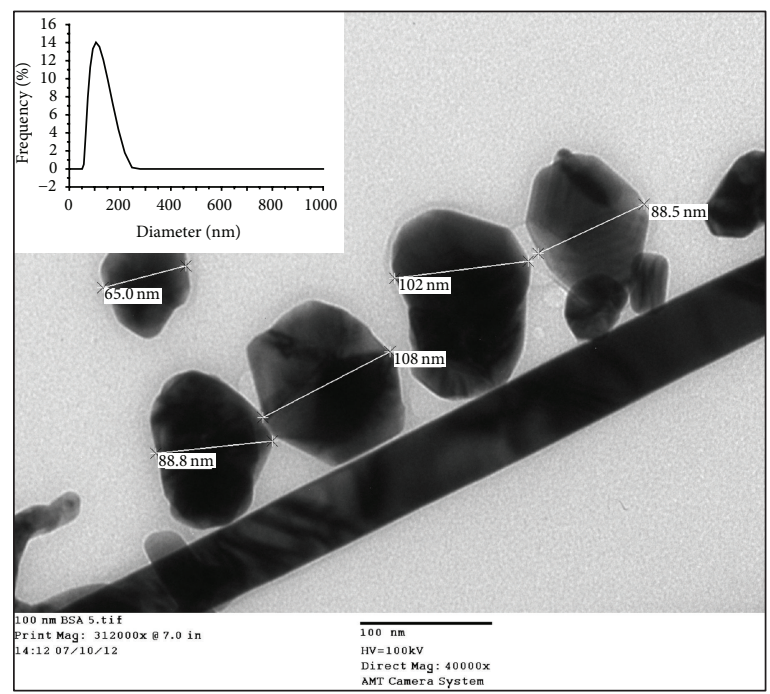

(c)

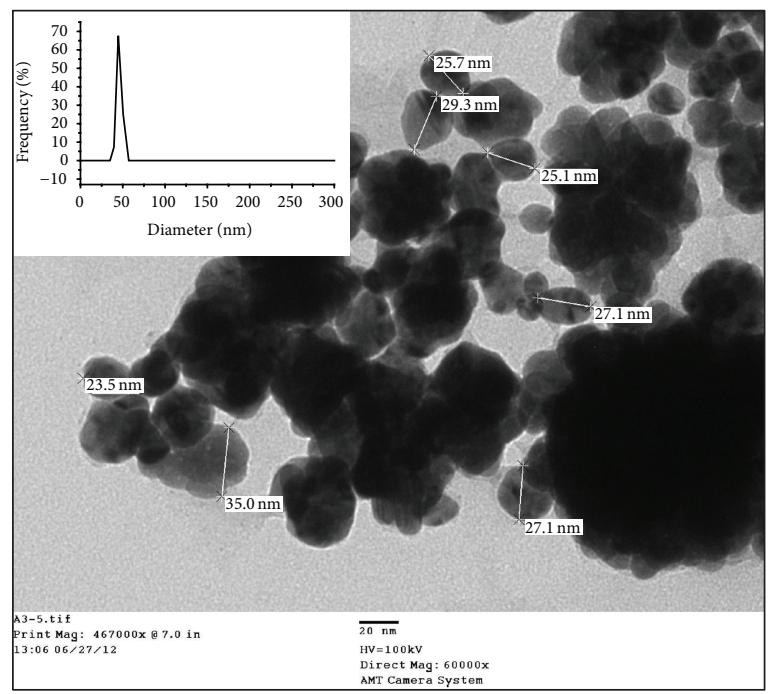

(e)

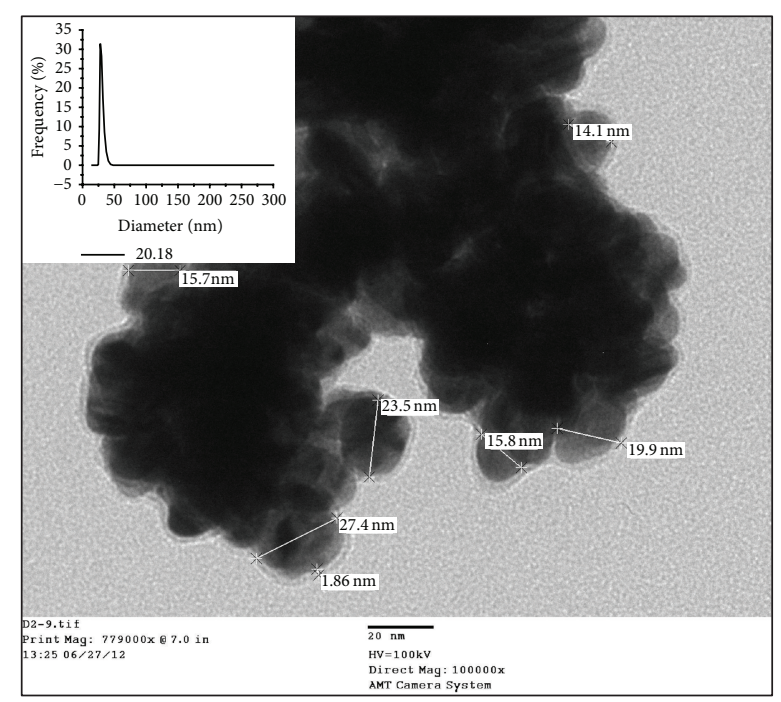

(b)

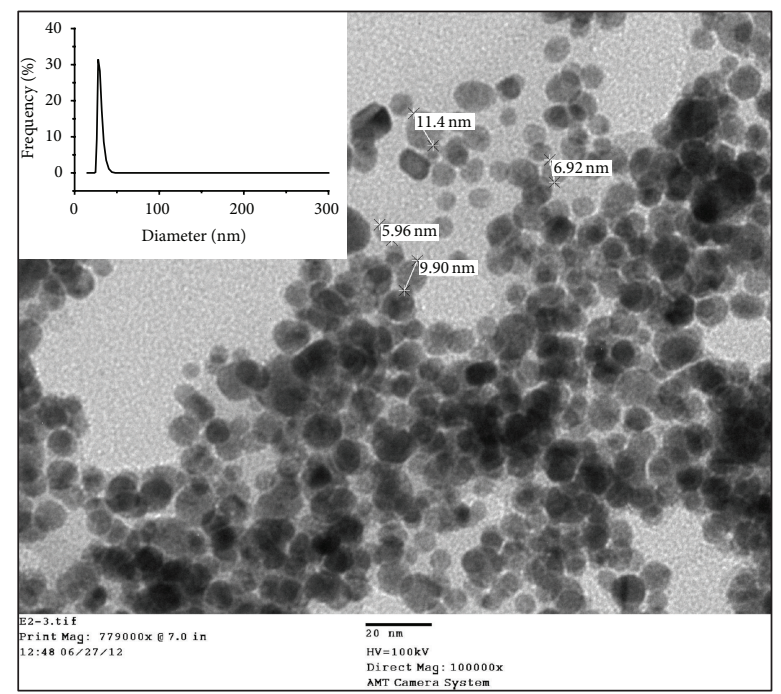

(d)

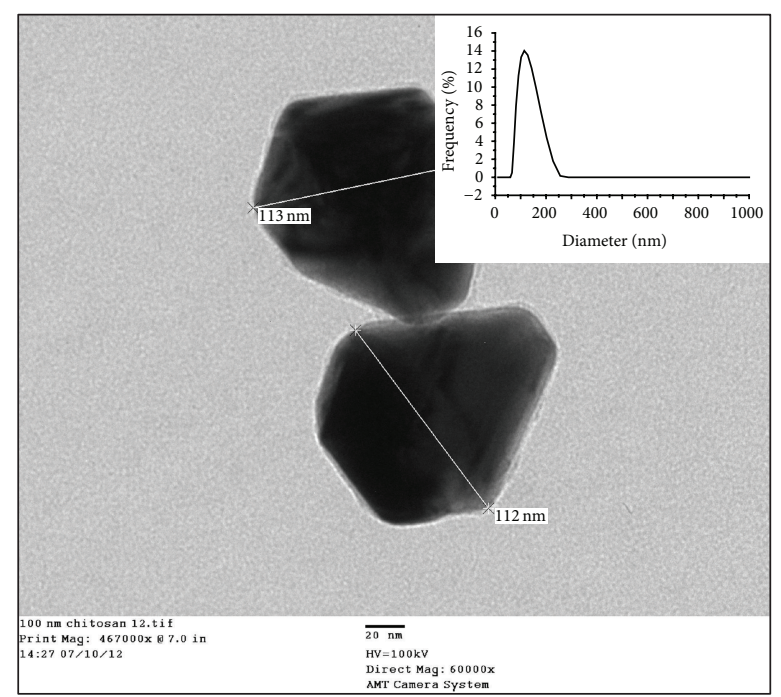

(f)

FIGURE 2: TEM micrographs and DLS analysis of BSA and CS coated SNP. (a) BSA $22.9 \mathrm{~nm}$; (b) BSA $32.7 \mathrm{~nm}$; (c) BSA $113.3 \mathrm{~nm}$; (d) CS $29.7 \mathrm{~nm}$; (e) CS $41.0 \mathrm{~nm}$; (f) CS $116.6 \mathrm{~nm}$. 


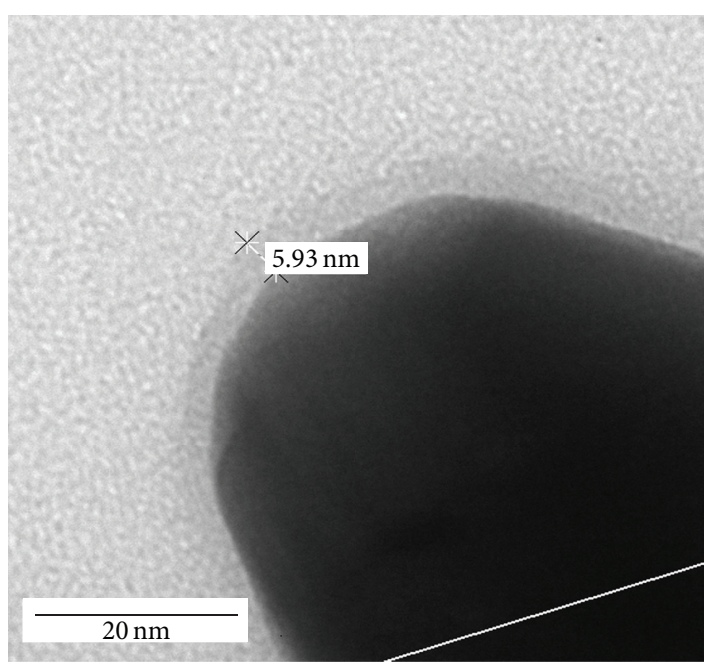

(a)

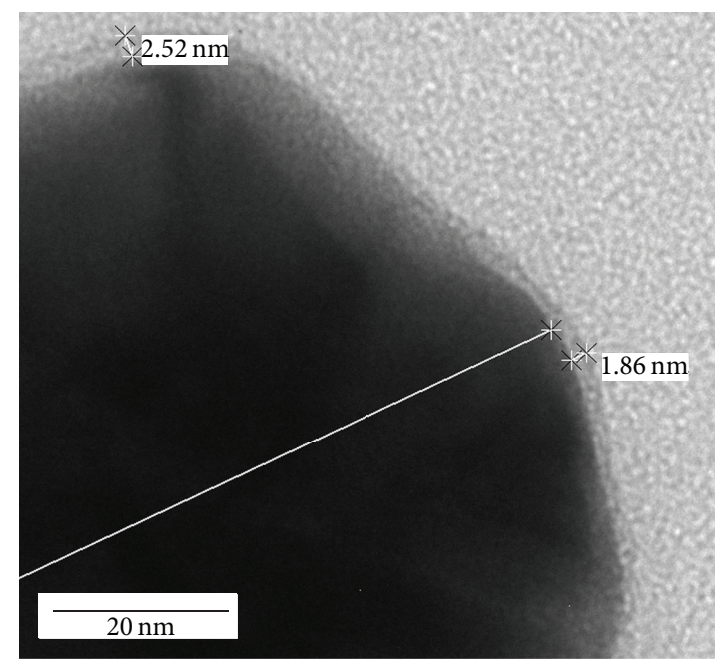

(b)

FIgURE 3: Core-shell structure of coated SNP by TEM. (a) BSA $113.3 \mathrm{~nm}$; (b) CS $116.6 \mathrm{~nm}$.

negative charge slightly when its size is larger; moreover, positive charges in CS samples compared to negative values in noncoated samples were also obtained. We can assume that BSA and CS components, due to their high affinity to bind to SNP surface attaching thiols and amino groups might be modifying electrical charges on the surface of SNP producing differences on surface charge of outer region of SNP [21, 22].

3.2. TEM Analysis. TEM micrographs of BSA and CS coated SNP are shown in Figure 2. We can realize that smaller BSA and CS coated SNP samples show uniform spherical shapes while bigger nanoparticles in both BSA and CS coated SNP are pseudospherical particles with irregular hexagonal shapes. Coated SNP exhibit acceptable dispersion and good size distribution, although some SNP agglomerates can be seen in BSA coated SNP of $19.4 \mathrm{~nm}$ (Figure 2(b)) due to strong interactions between $\mathrm{Ag}^{+}$and BSA forming conglomerations of many BSA molecules [23]. A small shell in BSA and CS coated SNP samples (BSA $113.3 \mathrm{~nm}$ and CS $116.6 \mathrm{~nm}$ samples) was also observed around the pseudospherical SNP (Figure 3); BSA coatings of $5.93 \mathrm{~nm}$ and $2.52 \mathrm{~nm}$ of CS were clearly observed showing thickness similarities with others studies $[24,25]$.

3.3. Thermal Analysis. TGA and DSC results are shown in Table 2. Weight loss differences were found between coated (BSA 3.24-13.07\% and CS 2.43-32.68\%) and noncoated (1.5$2.18 \%)$ SNP samples. TGA curves showed that coated SNP samples have different mass profile and considerable amount of BSA and CS compounds than noncoated SNP. Smaller BSA and CS coated SNP displayed a higher percentage of coating weight than larger nanoparticles; this may be easily explained due to the fact that smaller nanoparticles have a high reactive area to bind to thiol, amino, and hydroxyl groups of BSA and CS molecules, respectively [21, 26]. DSC results are shown in general two peaks; the first weight loss appeared from 18 to $110^{\circ} \mathrm{C}$ for coated and noncoated SNP indicating water loss $\left(18\right.$ to $\left.110^{\circ} \mathrm{C}\right)$ and the second peak, which corresponds to decomposition of BSA and CS components, started from $200-250^{\circ} \mathrm{C}$ up to $500^{\circ} \mathrm{C}$ and 250 up to $450^{\circ} \mathrm{C}$, respectively. TGA-DSC results suggest the presence of BSA and CS coatings on SNP surfaces due to the different mass profile obtained from BSA and CS coated SNP compared with noncoated SNP samples. Probably, BSA as plasma protein showed a strong affinity for SNP in order that SNP surfaces and $\mathrm{Ag}^{+}$ions could bind with proteins and amino acids present in BSA attaching with thiol groups providing steric stabilization due to the bulky protein molecules [21, 27, 28]. CS coated SNP can assume that CS macromolecules are attached with SNP using electrostatic interactions with the presence of a large number of free amino $\left(-\mathrm{NH}_{2}\right)$ and hydroxyl $(-\mathrm{OH})$ groups in CS chains forming bonds with SNP surfaces; the high affinity of CS from $\beta$ (1-4) D-glucosamine units to bind to $\mathrm{Ag}$ surfaces has been demonstrated by previous studies [24, 26, 29].

3.4. Antibacterial Assay. MIC results from BSA and CS coated SNP on Gram-negative bacterium of E. coli and Grampositive bacterium of $S$. aureus, E. faecalis, S. mutans, $S$. sobrinus, S. oralis, and S. salivarius are shown in Table 3. Coated and noncoated SNP samples showed different levels of antibacterial activity on different strains, although differences according to type of coatings, size of particle, and type of bacterium strain were also associated. For example, the antimicrobial effect of the two smaller nanoparticles was better in coated SNP than noncoated samples; moreover, the bigger size of BSA coated SNP sample showed higher growth inhibition than the other similar sizes of CS coated and noncoated SNP samples, respectively. The smallest coated and noncoated SNP samples obtained higher antimicrobial activity than bigger samples and the coating of CS sample showed the best inhibition activity. Furthermore, it can be observed in Figure 3 that poor bacterial adherence and low survival activities in bacterial strains (S. mutans) were 
TABLE 2: TGA and DSC analysis of BSA and CS coated SNP.

\begin{tabular}{|c|c|c|c|c|c|}
\hline Sample (nm) & First weight loss (\%) & Second weight loss (\%) & Residues (\%) & Total weight loss (\%) & Coating weight (\%) \\
\hline 10.7 & $0.02(18-110)$ & $1.41(150-500)$ & 98.5 & 1.5 & - \\
\hline 38.3 & $0.0(20-110)$ & $1.7(150-500)$ & 98.24 & 1.76 & - \\
\hline 110.8 & $0.17(20-100)$ & $1.84(200-500)$ & 97.82 & 2.18 & - \\
\hline BSA 22.9 & $0.38(21-100)$ & $3.4(200-500)$ & 96.37 & 3.63 & 2.13 \\
\hline BSA 32.7 & $1.32(21-110)$ & $11.44(200-500)$ & 86.93 & 13.07 & 11.31 \\
\hline BSA 113.3 & $0.33(21-100)$ & $2.74(210-500)$ & 96.76 & 3.24 & 1.06 \\
\hline CS 29.7 & $30.45(23.5-100)$ & $2.81(200-500)$ & 67.32 & 32.68 & 31.18 \\
\hline CS 41.0 & $0.16(20-100)$ & $2.39(150-500)$ & 97.57 & 2.43 & 0.67 \\
\hline CS 116.6 & $0.0(20-100)$ & $3.6(175-500)$ & 95.9 & 4.1 & 1.92 \\
\hline
\end{tabular}

First and second weight loss columns describe in parentheses the temperature range for each sample. - : not applicable.

TABLE 3: Minimal inhibitory concentrations (MIC) of BSA and CS coated SNP.

\begin{tabular}{|c|c|c|c|c|c|c|c|c|}
\hline SNP samples (nm) & S. aureus & E. coli & E. faecalis & S. mutans & S. sobrinus & S. oralis & S. salivarius & Total/SNP* \\
\hline 10.7 & $535.0 \pm 0.0$ & $535.0 \pm 0.0$ & $535.0 \pm 0.0$ & $222.9 \pm 77.2$ & $535.0 \pm 0.0$ & $535.0 \pm 0.0$ & $44.6 \pm 19.3$ & $420.4 \pm 202$ \\
\hline 38.3 & 1070.0 & $1070.0 \pm 0.0$ & $1070.0 \pm 0.0$ & 0.0 & $1070.0 \pm 0.0$ & $1070.0 \pm 0.0$ & 178.3 & $=363$ \\
\hline 110.8 & $1070.0 \pm 0.0$ & $1070.0 \pm 0.0$ & $1070.0 \pm 0.0$ & $1070.0 \pm 0.0$ & $1070.0 \pm 0.0$ & $1070.0 \pm 0.0$ & 178.3 & 337 \\
\hline BSA 22.9 & $469.2 \pm$ & $469.2 \pm 0.0$ & $469.2 \pm 0.0$ & $234.6 \pm 0.0$ & $469.2 \pm 0.0$ & $0 \pm 135$ & 5.9 & 167 \\
\hline BSA 32.7 & $998.9 \pm 0.0$ & $998.9 \pm 0.0$ & $998.9 \pm 0.0$ & $249.7 \pm 0.0$ & $998.9 \pm 0.0$ & $832.4 \pm 288$ & 41.6 & $731.3 \pm 409$ \\
\hline BSA 113.3 & $938.5 \pm 0.0$ & $938.5 \pm 0.0$ & $938.5 \pm 0.0$ & $469.2 \pm 0.0$ & $938.5 \pm 0.0$ & $938.5 \pm 0.0$ & $625.6 \pm 271$ & $826.8 \pm 196$ \\
\hline CS 29.7 & $525.6 \pm 0.0$ & $87.6 \pm 37.9$ & $525.6 \pm 0.0$ & $262.8 \pm 0.0$ & $262.8 \pm 0.0$ & $262.8 \pm 0.0$ & $262.8 \pm 0.0$ & $312.9 \pm 158$ \\
\hline CS 41.0 & $1033.1 \pm 0.0$ & $516.5 \pm 0.0$ & $1033.1 \pm 0.0$ & $688.7 \pm 298$ & $1033.1 \pm 0.0$ & $1033.1 \pm 0.0$ & $344.3 \pm 149.1$ & $811.7 \pm 293$ \\
\hline CS 116.6 & $1033.1 \pm 0.0$ & $1033.1 \pm 0.0$ & $1033.1 \pm 0.0$ & $1033.1 \pm 0.0$ & $1033.1 \pm 0.0$ & $1033.1 \pm 0.0$ & $688.7 \pm 298.3$ & $983.9 \pm 130$ \\
\hline Total/ $\mathrm{MO}^{\dagger}$ & $852 \pm 260$ & $746 \pm 353$ & $852 \pm 260$ & $529 \pm 336$ & $823 \pm 311$ & $796 \pm 316$ & $267 \pm 245$ & - \\
\hline
\end{tabular}

All values are measured in microgram per milliliter $(\mu \mathrm{g} / \mathrm{mL})$, average and standard deviation. Average values of MIC were obtained in triplicate. ${ }^{*}$ Total average per SNP sample. ${ }^{\dagger}$ Total average of MIC per microorganism. - : not applicable.

observed in smallest SNP samples compared to larger SNP in which CS samples showed slightly higher antiadherence characteristics in the most bacterial strains than BSA samples (Figure 4). The results can suggest that the antimicrobial activity of coated SNP might depend on the type of coating on the SNP surface producing a synergic mechanism that it improves the bacterial growth inhibition and the ability of SNP to bind to cell membranes and to generate antimicrobial effect; however, the large surface area of small SNP might also be involved $[26,30,31]$. The most resistant bacteria to SNP were presented by $S$. aureus and E. faecalis, followed by S. sobrinus, S. oralis, E. coli, S. mutans, and S. salivarius strains. The main Gram-positive (S. aureus and E. faecalis) and Gram-negative (E. coli) bacteria, which are associated with multidrug-resistance infections, showed differences on their MIC results. S. aureus and E. faecalis, as Gram-positive bacteria had similar higher MIC values $(852 \pm 260 \mu \mathrm{g} / \mathrm{mL})$ than Gram-negative bacteria of E. coli $(746 \pm 353 \mu \mathrm{g} / \mathrm{mL})$. The Gram-positive bacteria revealed the highest microbial resistance to SNP although E. coli bacteria can offer more antimicrobial inhibitory resistance than $S$. aureus strain to similar conditions [32]. Our findings agree with the majority of previous reports indicating an antimicrobial effect against several types of bacterial strains (including oral and nonoral bacteria), improving their antimicrobial activity when BSA and/or CS coatings are present $[24,26,32,33]$.

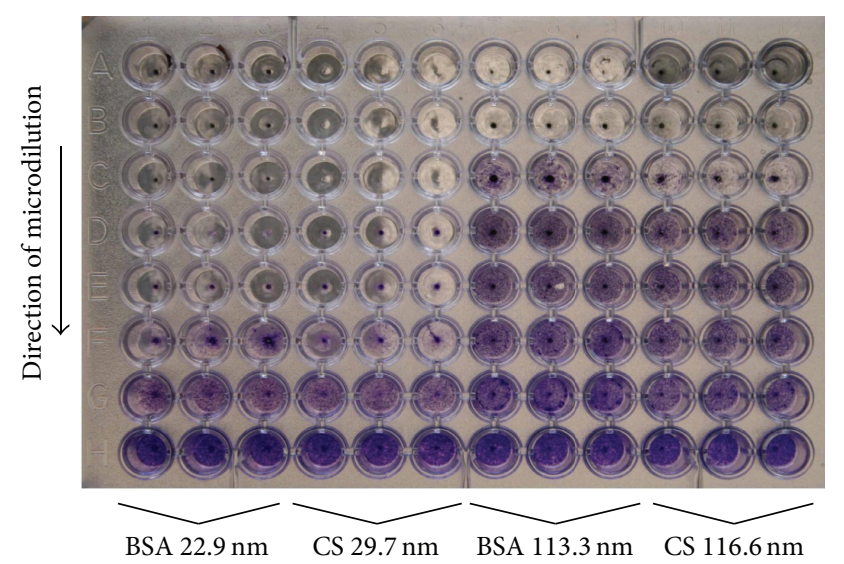

FIgURE 4: Antimicrobial activity of coated SNP against S. mutans strain (ATCC, 25175). Purple wells show bacterial growth.

It is possible that a combined antimicrobial action between SNP and coatings can be present. In BSA coated SNP, an antimicrobial mechanism of electrostatic interactions between the nanoparticles and the negatively charged cell surface [34], as well as the control in the interactions of nanoparticles with the cell by the protein on the nanoparticle surface, could be synergistically related [35]. Conversely, CS is 


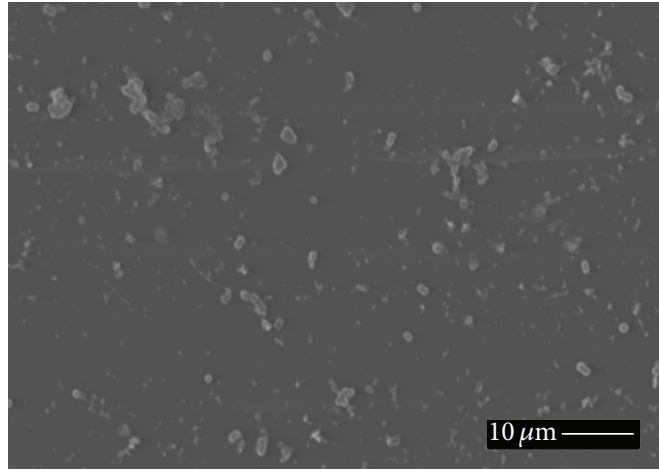

(a)

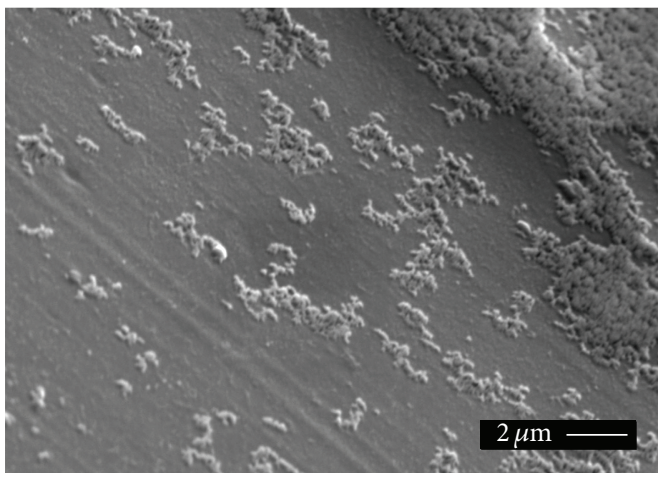

(c)

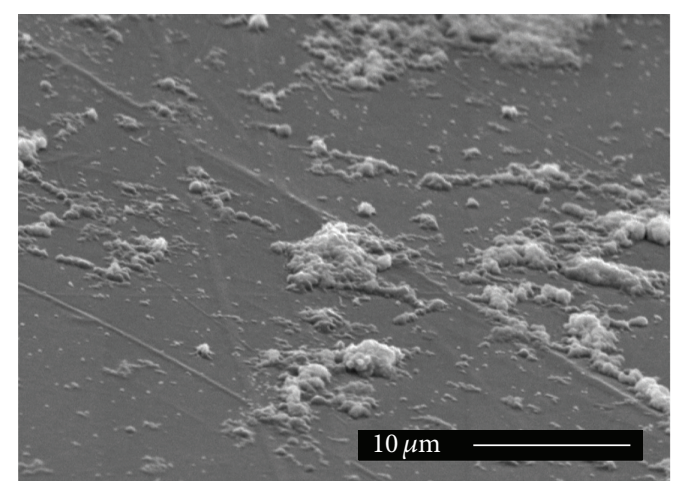

(b)

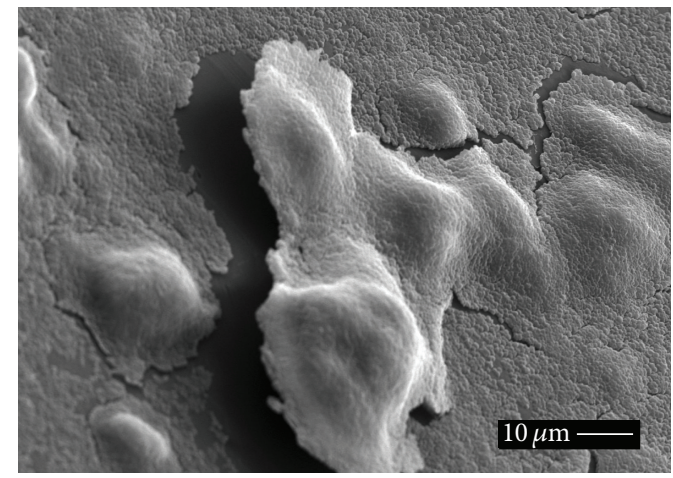

(d)

FIGURE 5: SEM micrographs of $S$. mutans bacteria treated with SNP. (a) Noncoated SNP (10.7 nm); (b) BSA-SNP (22.9 nm); (c) CS-SNP $(29.7 \mathrm{~nm}) ;(\mathrm{d})$ control (S. mutans).

considered unable to enter into the cell and their antibacterial effect would be only on the cell surface using electrostatic contacts that could bind and disrupt the cytoplasmic membrane of bacteria leading to damage of membrane functions [36]. Also, CS could help to alter the dynamic balance of Ag-O bond at the same time as CS interacted with bacterial membrane in order to result in free radicals, $\mathrm{Ag}^{+}$ions, and/or small SNP that may easily penetrate inside cells [26] inhibiting respiration process, activation of proteins, replication of DNA [37], and the possibility of the induction of a bacterial apoptosis-like response [38] leading to the cell death.

3.5. SEM Analysis. SEM micrographs of S. mutans cells treated with small coated (BSA $22.9 \mathrm{~nm}$ and $29.7 \mathrm{~nm}$ ) and noncoated $(10.7 \mathrm{~nm}) \mathrm{SNP}$ at the minimum inhibitory concentration are shown in Figure 5. Micrographs showed inhibition zones and alterations of the biofilm structure in coated (BSA $22.9 \mathrm{~nm}$ and $29.7 \mathrm{~nm}$ ) and noncoated $(10.7 \mathrm{~nm})$ SNP than control group. Poor growing of bacteria cells on wall surfaces was observed in the coated (Figures 5(b) and 5(c)) and noncoated (Figure 5(a)) SNP finding isolated cells and significant alterations of the bacteria cell bindings. It can also be seen that noncoated SNP (Figure 5(a)) modified much more the morphological structure of the biofilm and the shape of cells than those SNP with BSA and CS coatings (Figures 5 (b) and 5(c)). It is very probable that both coated and noncoated SNP can promote alterations of biofilm structure and cellular binding due to the limited production of free glucosyltransferases (cellular binding's principal enzyme) to produce glucans, extracellular polysaccharides, and cellular breathing from bacteria metabolism [20] leading to death; moreover, other specific types of bacteria cell membranes could be involved according to their metabolisms. BSA and CS coated SNP were less aggressive on $S$. mutans cells than noncoated SNP; this may indicate that coated SNP could have a low toxicological potential in cells due to limited interactions between SNP surfaces and cell membranes; therefore, other in vitro and in vivo studies are necessary to understand coated SNP's action mechanism.

\section{Conclusions}

SNP with different sizes, shapes, and BSA and CS coatings were successfully prepared and characterized. The coated SNP showed good antibacterial activity against seven oral and nonoral bacteria strains. The antimicrobial effectiveness of the coated SNP was associated with the size of the SNP; the presence and type of coating on the particle surface, principally CS component, produced significant antimicrobial activity thus suggesting a combination of various antimicrobial mechanisms that may depend on specific properties of SNP and individual characteristics of microorganisms. Biofunctionalization of SNP using organic components might 
be promising candidates for several biomedical applications. According to our knowledge, this is the first study where BSA and CS coated SNP were prepared with different sizes and shapes and their antimicrobial effects on seven oral and nonoral microorganisms were tested. Certainly, further investigations are necessary for a better understanding of coated SNP and their potential use for prevention and/or control of diseases considered as public health problems.

\section{Conflict of Interests}

The authors declare that there is no conflict of interests regarding the publication of this paper.

\section{Acknowledgments}

The authors are grateful for the financial support for this work: Consejo Nacional de Ciencia y Tecnología (CONACYT) (Grant 204948; Grant 169020) and Programa para el Desempeño Profesional Docente (PRODEP, Grant PROMEP/ 103.5/13/6610).

\section{References}

[1] R. Pena-Miller, D. Laehnemann, G. Jansen et al., "When the most potent combination of antibiotics selects for the greatest bacterial load: the smile-frown transition," PLoS Biology, vol. 11, no. 4, Article ID e1001540, 2013.

[2] P. C. Appelbaum, "The emergence of vancomycin-intermediate and vancomycin-resistant Staphylococcus aureus," Clinical Microbiology and Infection, vol. 12, no. 1, pp. 16-23, 2006.

[3] S. Asadi, M. Kargar, K. Solhjoo, A. Najafi, and S. GhorbaniDalini, "The Association of virulence determinants of uropathogenic Escherichia coli with antibiotic resistance," Jundishapur Journal of Microbiology, vol. 7, no. 5, Article ID e9936, 2014.

[4] C. A. Arias and B. E. Murray, "The rise of the Enterococcus: beyond vancomycin resistance," Nature Reviews Microbiology, vol. 10, no. 4, pp. 266-278, 2012.

[5] S. H. Siddiqui, K. H. Awan, and F. Javed, "Bactericidal efficacy of photodynamic therapy against Enterococcus faecalis in infected root canals: a systematic literature review," Photodiagnosis and Photodynamic Therapy, vol. 10, no. 4, pp. 632-643, 2013.

[6] K. A. Plonka, M. L. Pukallus, A. G. Barnett, L. J. Walsh, T. H. Holcombe, and W. K. Seow, "Mutans streptococci and lactobacilli colonization in predentate children from the neonatal period to seven months of age," Caries Research, vol. 46, no. 3 , pp. 213-220, 2012.

[7] J. Loyola-Rodriguez, J. Garcia-Cortes, R. Martinez-Martinez et al., "Molecular identification and antibiotic resistant bacteria isolated from primary dentition infections," Australian Dental Journal, vol. 59, no. 4, pp. 497-503, 2014.

[8] C. A. Arias, G. A. Contreras, and B. E. Murray, "Management of multidrug-resistant enterococcal infections," Clinical Microbiology and Infection, vol. 16, no. 6, pp. 555-562, 2010.

[9] T. Walsh, H. V. Worthington, A.-M. Glenny, P. Appelbe, V. C. Marinho, and X. Shi, "Fluoride toothpastes of different concentrations for preventing dental caries in children and adolescents," The Cochrane Database of Systematic Reviews, vol. 20, no. 1, Article ID CD007868, 2010.
[10] S. B. Bhardwaj, M. Mehta, and K. Gauba, "Nanotechnology: role in dental biofilms," Indian Journal of Dental Research, vol. 20, no. 4, pp. 511-513, 2009.

[11] Q. L. Feng, J. Wu, G. Q. Chen, F. Z. Cui, T. N. Kim, and J. O. Kim, "A mechanistic study of the antibacterial effect of silver ions on Escherichia coli and Staphylococcus aureus," Journal of Biomedical Materials Research, vol. 52, no. 4, pp. 662-668, 2000.

[12] L. Braydich-Stolle, S. Hussain, J. J. Schlager, and M.-C. Hofmann, "In vitro cytotoxicity of nanoparticles in mammalian germline stem cells," Toxicological Sciences, vol. 88, no. 2, pp. 412-419, 2005.

[13] J. Ai, E. Biazar, M. Jafarpour et al., "Nanotoxicology and nanoparticle safety in biomedical designs," International Journal of Nanomedicine, vol. 6, pp. 1117-1127, 2011.

[14] M. Marini, S. De Niederhausern, R. Iseppi et al., "Antibacterial activity of plastics coated with silver-doped organic-inorganic hybrid coatings prepared by sol-gel processes," Biomacromolecules, vol. 8, no. 4, pp. 1246-1254, 2007.

[15] J. Virkutyte and R. S. Varma, “Green synthesis of metal nanoparticles: biodegradable polymers and enzymes in stabilization and surface functionalization," Chemical Science, vol. 2, no. 5, pp. 837-846, 2011.

[16] S. Ashoka, J. Seetharamappa, P. B. Kandagal, and S. M. T. Shaikh, "Investigation of the interaction between trazodone hydrochloride and bovine serum albumin," Journal of Luminescence, vol. 121, no. 1, pp. 179-186, 2006.

[17] W. Xia, P. Liu, J. Zhang, and J. Chen, "Biological activities of chitosan and chitooligosaccharides," Food Hydrocolloids, vol. 25, no. 2, pp. 170-179, 2011.

[18] M. N. Nadagouda and R. S. Varma, "Green synthesis of silver and palladium nanoparticles at room temperature using coffee and tea extract," Green Chemistry, vol. 10, no. 8, pp. 859-862, 2008.

[19] M. N. Nadagouda, N. Iyanna, J. Lalley, C. Han, D. D. Dionysiou, and R. S. Varma, "Synthesis of silver and gold nanoparticles using antioxidants from blackberry, blueberry, pomegranate and turmeric extracts," ACS Sustainable Chemistry and Engineering, vol. 2, no. 7, pp. 1717-1723, 2014.

[20] L. F. Espinosa-Cristóbal, G. A. Martinez-Castanon, R. E. Martínez-Martínez et al., "Antimicrobial sensibility of Streptococcus mutans serotypes to silver nanoparticles," Materials Science and Engineering C, vol. 32, no. 4, pp. 896-901, 2012.

[21] A. Gebregeorgis, C. Bhan, O. Wilson, and D. Raghavan, "Characterization of silver/bovine serum albumin (Ag/BSA) nanoparticles structure: morphological, compositional, and interaction studies," Journal of Colloid and Interface Science, vol. 389, no. 1, pp. 31-41, 2013.

[22] S. W. Ali, S. Rajendran, and M. Joshi, "Synthesis and characterization of chitosan and silver loaded chitosan nanoparticles for bioactive polyester," Carbohydrate Polymers, vol. 83, no. 2, pp. 438-446, 2011.

[23] A. Ravindran, A. Singh, A. M. Raichur, N. Chandrasekaran, and A. Mukherjee, "Studies on interaction of colloidal Ag nanoparticles with Bovine Serum Albumin (BSA)," Colloids and Surfaces B: Biointerfaces, vol. 76, no. 1, pp. 32-37, 2010.

[24] H. V. Tran, L. D. Tran, C. T. Ba et al., "Synthesis, characterization, antibacterial and antiproliferative activities of monodisperse chitosan- based silver nanoparticles," Colloids and Surfaces A: Physicochemical and Engineering Aspects, vol. 360, no. 1-3, pp. 32-40, 2010. 
[25] R. Liu, F. Sun, L. Zhang et al., "Evaluation on the toxicity of nanoAg to bovine serum albumin," The Science of the Total Environment, vol. 407, no. 13, pp. 4184-4188, 2009.

[26] J. An, Z. Ji, D. Wang, Q. Luo, and X. Li, "Preparation and characterization of uniform-sized chitosan/silver microspheres with antibacterial activities," Materials Science and Engineering C, vol. 36, no. 1, pp. 33-41, 2014.

[27] D. V. Quang, J. E. Lee, J.-K. Kim, Y. N. Kim, G. N. Shao, and H. T. Kim, "A gentle method to graft thiol-functional groups onto silica gel for adsorption of silver ions and immobilization of silver nanoparticles," Powder Technology, vol. 235, pp. 221-227, 2013.

[28] E. M. S. Azzam and A. A. Abd El-Aal, "Corrosion inhibition efficiency of synthesized poly 12-(3-amino phenoxy) dodecane1-thiol surfactant assembled on silver nanoparticles," Egyptian Journal of Petroleum, vol. 22, no. 2, pp. 293-303, 2013.

[29] F. M. Reicha, A. Sarhan, M. I. Abdel-Hamid, and I. M. ElSherbiny, "Preparation of silver nanoparticles in the presence of chitosan by electrochemical method," Carbohydrate Polymers, vol. 89, no. 1, pp. 236-244, 2012.

[30] R. A. Bakare, C. Bhan, and D. Raghavan, "Synthesis and characterization of collagen grafted poly(hydroxybutyrate-valerate) (PHBV) scaffold for loading of bovine serum albumin capped silver (Ag/BSA) nanoparticles in the potential use of tissue engineering application," Biomacromolecules, vol. 15, no. 1, pp. 423-435, 2014.

[31] M. Lavorgna, I. Attianese, G. G. Buonocore et al., "MMTsupported Ag nanoparticles for chitosan nanocomposites: structural properties and antibacterial activity," Carbohydrate Polymers, vol. 102, no. 1, pp. 385-392, 2014.

[32] T. V. Mathew and S. Kuriakose, "Studies on the antimicrobial properties of colloidal silver nanoparticles stabilized by bovine serum albumin," Colloids and Surfaces B: Biointerfaces, vol. 101, pp. 14-18, 2013.

[33] Z. Lu, K. Rong, J. Li, H. Yang, and R. Chen, "Size-dependent antibacterial activities of silver nanoparticles against oral anaerobic pathogenic bacteria," Journal of Materials Science: Materials in Medicine, vol. 24, no. 6, pp. 1465-1471, 2013.

[34] L. Treuel, S. Brandholt, P. Maffre, S. Wiegele, L. Shang, and G. U. Nienhaus, "Impact of protein modification on the protein corona on nanoparticles and nanoparticle-cell interactions," ACS Nano, vol. 8, no. 1, pp. 503-513, 2014.

[35] C. C. Fleischer and C. K. Payne, "Nanoparticle-cell interactions: molecular structure of the protein corona and cellular outcomes," Accounts of Chemical Research, vol. 47, no. 8, pp. 2651-2659, 2014.

[36] H. Xu, L. Ma, H. Shi, C. Gao, and C. Han, "Chitosan-hyaluronic acid hybrid film as a novel wound dressing: in vitro and in vivo studies," Polymers for Advanced Technologies, vol. 18, no. 11, pp. 869-875, 2007.

[37] H. J. Klasen, "A historical review of the use of silver in the treatment of burns. II. Renewed interest for silver," Burns, vol. 26, no. 2, pp. 131-138, 2000.

[38] W. Lee, K.-J. Kim, and D. G. Lee, "A novel mechanism for the antibacterial effect of silver nanoparticles on Escherichia coli," BioMetals, vol. 27, no. 6, pp. 1191-1201, 2014. 

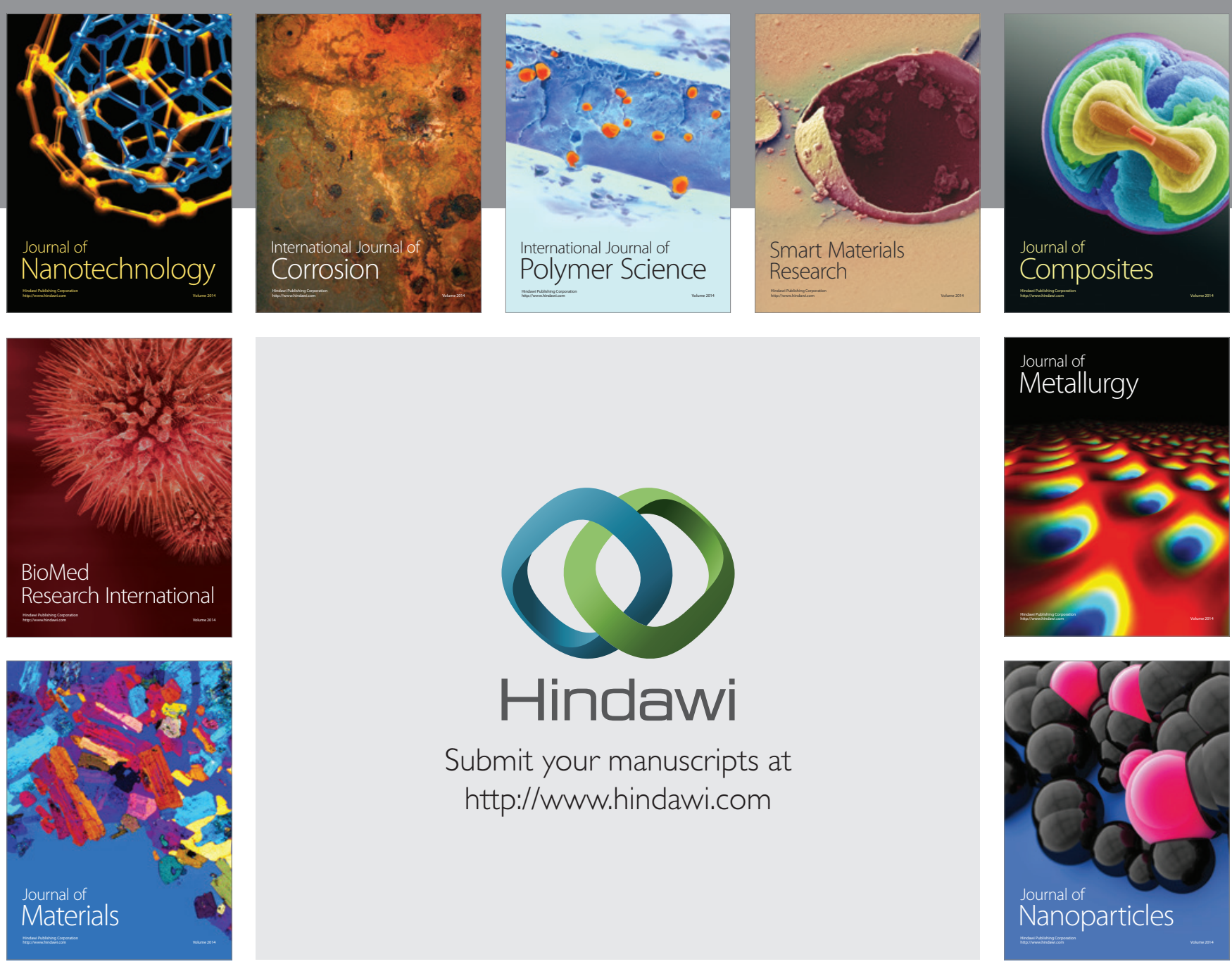

Submit your manuscripts at http://www.hindawi.com
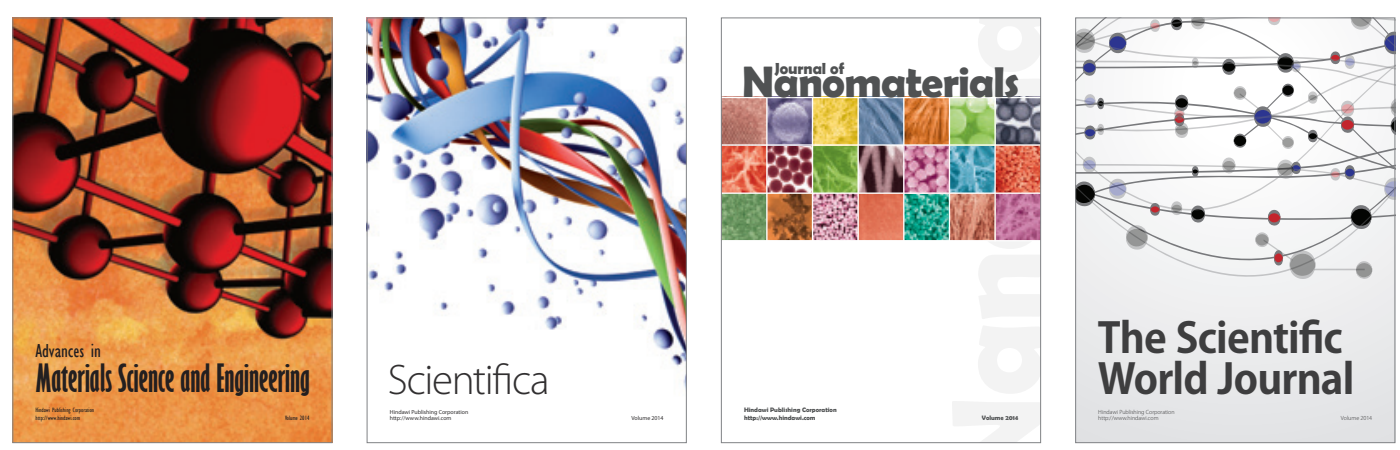

\section{The Scientific World Journal}
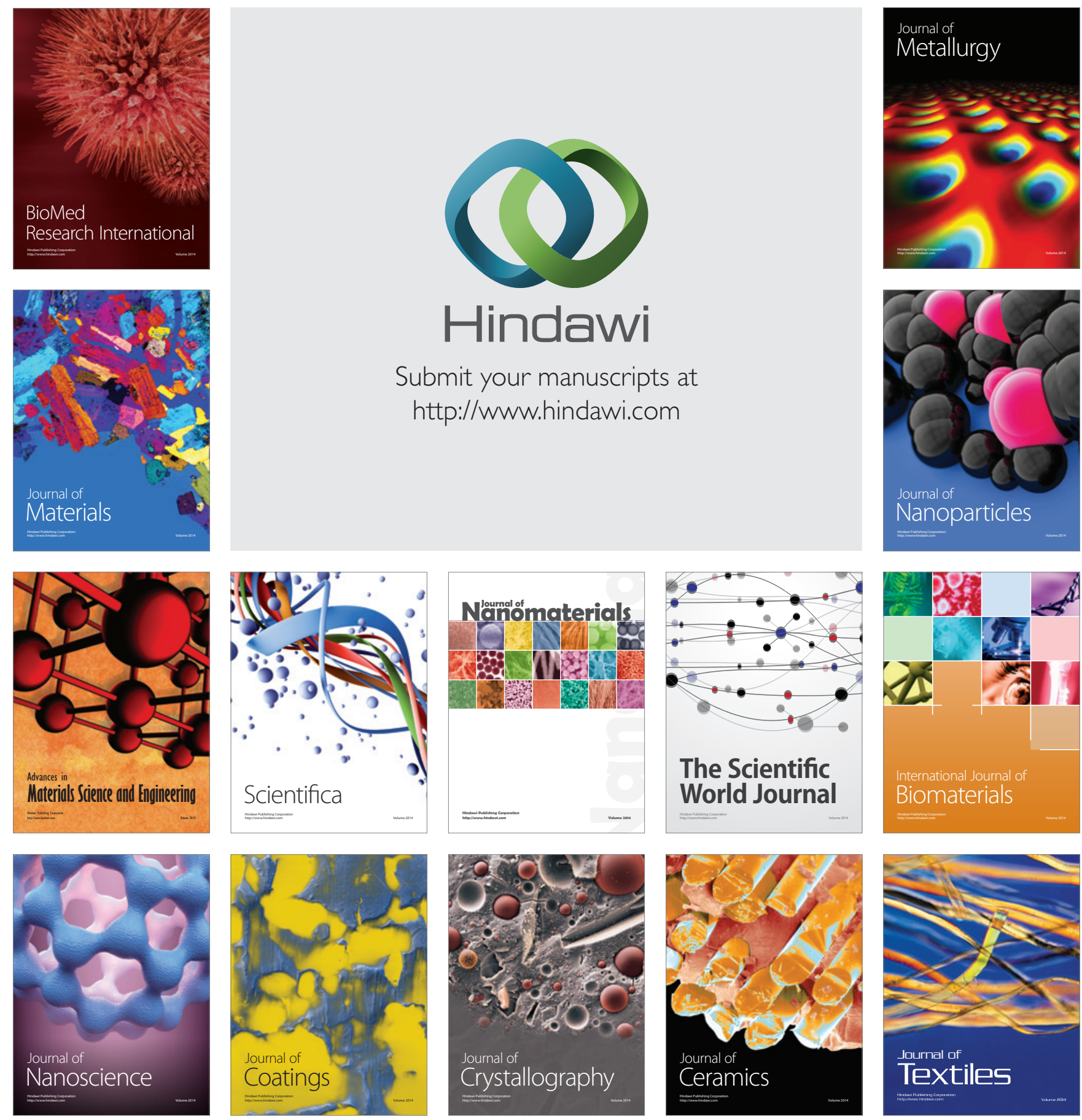